\title{
Fire, climate and biomes - towards a better understanding of this complex relationship
}

\author{
Anne-Laure Daniau' and Tim Brücher ${ }^{2}$ \\ Global Paleofire Working Group 2 workshop, Beguey, France, 25-29 September 2016
}

The Global Paleofire Working Group phase 2 (GPWG2) is extending its focus to address linkages between fire and climate-driven fuel changes, traditional and modern human landuse management and biodiversity conservation issues. Thirty-two researchers from 11 countries with expertise in paleofire, biogeography and fire ecology, paleoclimate, expert assessment, and climate and fire modeling participated in this first meeting.

In recent years, variations in past fire activity have been mainly described by compositing fire signals geographically over large areas with heterogeneous vegetation or even climate-driven vegetation shifts. In contrast to that, the key purpose of this workshop, titled "Fire history baselines by biome", was to reconstruct fire activity based on vegetation patterns. We identified several approaches for such comparisons and discussed concepts based on regions with an underlying homogeneous vegetation (i.e. biomes; Fig. 1). These approaches range from testing fire vs. biome modeling to the study of fire traits, i.e. interactions between plants and fire that are explicitly described by a set of fire-specific plant functions. Ideas also emerged to investigate deviations from a "baseline" as past reference characteristics of a fire regime within a certain ecosystem (under stable-state conditions).
Model-data comparison based on the forthcoming FireMIP experiments offers another opportunity to better understand fire-vegetation interactions in the Earth system. In this regard, discussions focused on Last Glacial Maximum (LGM) to present comparisons, the experimental design, and on challenges in model-data comparison. The latter point related to the reduced number of sites for LGM to compare with and the interpretation of the time series within the Global Charcoal Database given as normalized trends. Such relative changes in past fire regimes limit the messages and possibilities that can be drawn out of these model-data comparisons.

Many of the discussions stressed the importance of calibration studies to obtain quantified and precise reconstructions of past fire regime metrics (fire size, intensity, frequency, etc.). GPWG2 launched a calibration initiative to build a "modern Global Charcoal Database", which will provide the possibility to analyze fire activity based on absolute numbers and a uniform and consistent set of charcoal units. This will allow a better interpretation and detailed intercomparison of charcoal records. Furthermore, upcoming model-data studies based on quantifiable variations in fire activity (i.e. fire regime metrics) will be possible. During the meeting, the next steps of

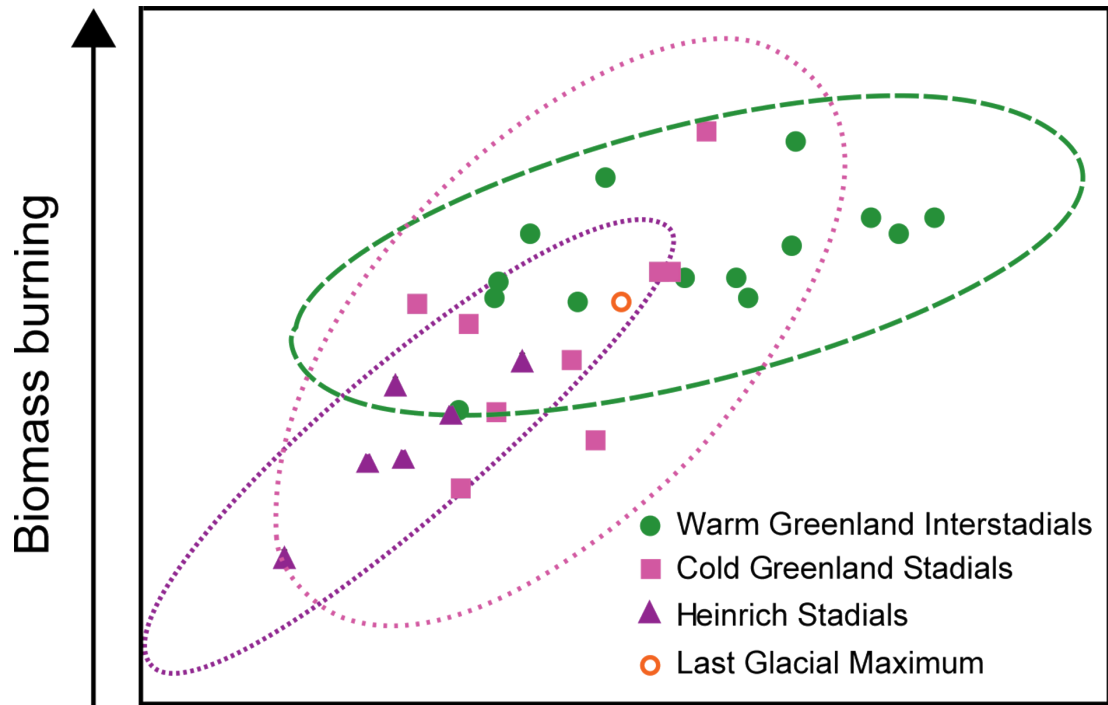

Climate/Biome
Mediterranean forest
Mediterranean forest

Figure 1: Fire-vegetation-climate interaction during abrupt climate change of the last glacial periodin the the dominant vegetation was characterized by semi-desert vegetation. The fuel-limited environment restricted biomass burning activity. The increase of regional temperature and humidity at the time of warm periods (Greenland Interstadial) led to a fire regime and vegetation shift towards increased biomass burning. this calibration endeavor were addressed and preliminary results suggest that calibration is possible when field, laboratory and analysis methods are consistent.

General statements on the risk of fires and the change of fire-danger indices in the IPCC indicate that both seem to increase under global warming. However, these indices are built upon simple assumptions rather than on detailed model analysis using dynamical vegetation-fire models including the interaction of all feedbacks (like fuel productivity influenced by the atmospheric $\mathrm{CO} 2$ fertilization). To propose a better evaluation for the next IPCC report, the workshop participants designed an expert assessment survey on the likelihood of future fire regime change for different climate-change scenarios. This assessment will focus on different Representative Concentration Pathways climate scenarios and compile the expert knowledge of modelers, field researchers and paleo-fire experts about the most relevant factors influencing fire regime in a particular region at different timescales.

The workshop also fostered connections be tween GPWG2 and two INQUA International Focus Groups - ACER and FBI-HYD. The development of a chronologically harmonized dataset of pollen and charcoal for the last glacial period (ACER) will allow analyses of fire-vegetation interactions in response to abrupt climate change (Fig. 1), and the cooperation with FBI-HYD, which examines fire-hydrology linkages in southern Africa, will expand the possibility of integrating the hydrological balance into vegetation-fire modeling in subtropical regions.

\section{ACKNOWLEDGEMENTS}

PAGES, PICS CNRS 06484 project, CNRS-INSU, Région Nouvelle-Aquitaine, University of Bordeaux DRI and INQUA are acknowledged for workshop support.

\section{AFFILIATIONS}

Environnements et Paléoenvironnements Océaniques et Continentaux, CNRS-University of Bordeaux, Pessac, France

${ }^{2} \mathrm{Helmholtz}$ Centre for Ocean Research, GEOMAR, Kiel, Germany

\section{CONTACT}

Anne-Laure Daniau: al.daniau@epoc.u-bordeaux1.fr

REFERENCE

Daniau AL et al. (2010) PLoS ONE 5, doi: 10.1371/journal. pone.0009157 